\title{
Caracterização química e perfil de ácidos graxos em cultivares de nogueira-macadâmia
}

\author{
Chemical characterization and fatty acids profile in macadamia walnut cultivars
}

\author{
Luana Aparecida Castilho Maro ${ }^{\mathrm{I}}$ Rafael Pio ${ }^{\text {I* }}$ Edwaldo dos Santos Penoni ${ }^{\mathrm{I}}$ \\ Marcelo Caetano de Oliveira ${ }^{\mathrm{I}}$ Fernanda Costa Prates ${ }^{\mathrm{II}}$ Luiz Carlos de Oliveira Lima ${ }^{\mathrm{II}}$ \\ Maria das Graças Cardoso ${ }^{\mathrm{II}}$
}

\section{RESUMO}

A nogueira-macadâmia produz nozes de alto valor no mercado internacional, devido às características nutricionais de suas amêndoas, consideradas uma excelente fonte energética. $O$ objetivo do trabalho foi realizar a caracterização química e o perfil de ácidos graxos em 22 cultivares de nogueiramacadâmia. As cultivares utilizadas foram: 'Edson', 'HAES 788 (Pahala)', 'Beaumont 695', 'Flor Rosa', 'IAC 9-20X', 'HAES 344 (Kau)', 'Cannon', 'IAC 9-20', 'C160', 'HAES 849', 'IAC 4-12B', 'HAES 816', 'Doroti', '791 Fuji', 'IAC 420 (Keaumi)', 'HAES 814', 'HAES 722', 'África', 'IAC Campinas-B', 'HAES 246 (Keauhou)', 'HAES 741 (Mauka)' $e$ 'HAES 842'. Foram quantificados a umidade, extrato etéreo, proteína, cinza e fibra bruta, além disso, extração de óleo e o perfil de ácidos graxos. A maior quantidade de proteína foi registrada na cultivar 'IAC 9-20X'. Quanto ao teor de fibra bruta, as maiores porcentagens foram observadas nas cultivares 'HAES 741'e 'HAES 842'. As amêndoas de todas as cultivares de nogueira-macadâmia analisadas possuem ácidos palmítico e oleico.

Palavras-chave: Macadamia integrifolia, composição química, cromatografia.

\section{ABSTRACT}

The walnuts macadamia have a high value on the international market due to their almonds nutritional characteristics considered to be an excellent source of energy. The aim of this work was to evaluate the chemical composition and fatty acid profile of 22 cultivars of almond walnut macadamia. The cultivars tested were: 'Edson', 'HAES 788 (Pahala)', 'Beaumont 695', 'Flor Rosa', 'IAC 9-20X', 'HAES 344 (Kau)', 'Cannon', 'IAC 9-20', 'C160', 'HAES 849', 'IAC

\begin{abstract}
4-12B', 'HAES 816', 'Doroti', '791 Fuji', 'IAC 4-20 (Keaumi)', 'HAES 814', 'HAES 722', 'África', 'IAC CampinasB', 'HAES 246 (Keauhou)', 'HAES 741 (Mauka)' and 'HAES 842'. Moisture, fat, protein, ash and crude fiber were analyzed and also oil extraction and fatty acid profile. The highest amount of protein was recorded in 'IAC 9-20X'. The highest percentages of crude fiber content were observed in cultivars 'HAES 741' and 'HAES 842'. The kernels of all walnut macadamia cultivars showed palmitic and oleic acids.
\end{abstract}

Key words: Macadamia integrifolia, chemical composition, chromatography.

\section{INTRODUÇÃO}

As nozes verdadeiras (amêndoas) são frutas secas com altos valores proteicos e lipídicos. As mais conhecidas são a amêndoa, pecã, castanha-do-pará, castanha-de-cajú, nogueira-macadâmia, pistache e avelã. Em relação à qualidade proteica, as nozes apresentam, de forma geral, um perfil de aminoácidos essenciais que atende a maior parte das necessidades diárias. Além disso, as nozes comestíveis são fontes de outros nutrientes e substâncias com propriedades medicinais, denominados de compostos biologicamente ativos. Dentre eles, destacam-se os ácidos graxos, contendo, sobretudo, os ácidos oleico e linoleico (VENKATACHALAM \& SATHE, 2006). A caracterização química e o perfil de ácidos graxos de

'Departamento de Agricultura, Universidade Federal de Lavras (UFLA), CP 3037, 372000-000, Lavras, MG, Brasil. E-mail: rafaelpio@dag.ufla.br. *Autor para correspondência.

IDepartamento de Ciência dos Alimentos, UFLA, Lavras, MG, Brasil.

IIIDepartamento de Química, UFLA, Lavras, MG, Brasil. 
uma série de nozes e sementes comestíveis foram traçados por FREITAS \& NAVES (2010) e, no caso da nogueira-macadâmia (Macadamia integrifolia Maiden \& Betche), não foi destacada a procedência varietal das amêndoas que foram utilizadas nas análises.

Existe uma série de cultivares de nogueiramacadâmia selecionada principalmente pelos programas de melhoramento genético do Havaí, onde foram lançadas as cultivares de nogueira-macadâmia da série HAES (Hawaii Agricultural Experiment Station), como 'Pahala' (HAES 788), 'Kau' (HAES 344), 'Keauhou' (HAES 246), 'Mauka' (HAES 741), 'Ikaika' (HAES 333), 'Kakea' (HAES 508), 'Keaau' (HAES 660), 'Makai' (HAES 800), dentre outras de menor importância comercial (PEACE et al., 2005). No Brasil, os trabalhos de melhoramento genético com a nogueiramacadâmia foram realizados, inicialmente, pelo Instituto Agronômico de Campinas (IAC), que visou, sobretudo, à seleção de cultivares produtivas e adaptadas às condições climáticas do Estado de São Paulo (SOBIERAJSKI et al., 2006; BASTOS et al., 2006). Apesar da grande quantidade de cultivares disponíveis nesse estado, maior produtor nacional, apenas são cultivadas 'Keauhou', 'Mauka', 'IAC Campinas-B' e 'IAC 9-20' (BARBOSA et al., 2003).

Segundo PENONI et al. (2011) e DALASTRA et al. (2010), há diferenças marcantes nas dimensões dos frutos e amêndoas entre as cultivares de nogueiramacadâmia. Acredita-se que há diferença significativa na constituição das amêndoas entre as diferentes cultivares, com isso, a determinação da composição química e o perfil de ácidos graxos poderiam auxiliar na escolha de cultivares que apresentem amêndoas com qualidade química superior, visando ao processamento ou mesmo à seleção de progenitores para programas de melhoramento genético.

\section{MATERIAIS E MÉTODOS}

A coleta das nozes de nogueiras-macadâmia para análise foi realizada na safra do ano de 2011, na propriedade denominada Sítio das Palmeiras, situada no município de Itapira-SP, a uma latitude de $22^{\circ} 26^{\prime} 00^{\prime \prime}$ e longitude de 46 49' $18^{\prime \prime}$ e altitude de $675 \mathrm{~m}$. O clima local, segundo classificação de Köeppen, é mesotérmico de inverno seco ( $\mathrm{Cwa}$ ), comumente chamado de tropical de altitude, com temperatura anual média de $18^{\circ} \mathrm{C}$ e precipitação média anual de $1.300 \mathrm{~mm}$.

As cultivares de nogueira-macadâmia utilizadas foram: 'Edson', 'HAES 788 (Pahala)', 'Beaumont 695', 'Flor Rosa', 'IAC 9-20X', 'HAES 344 (Kau)', 'Cannon', 'IAC 9-20', 'C160', 'HAES 849', 'IAC 4-12B', 'HAES 816', 'Doroti', '791 Fuji', 'IAC 4-20
(Keaumi)', 'HAES 814', 'HAES 722', 'África', 'IAC Campinas-B', 'HAES 246 (Keauhou)', 'HAES 741 (Mauka)' e 'HAES 842'. Todas as plantas possuíam cinco anos de idade e receberam os tratos culturais indicados para a cultura.

$\mathrm{Na}$ primeira etapa, para cada cultivar avaliada, foram coletados 100 frutos aleatoriamente em quatro diferentes plantas, que foram divididos em quatro repetições de 25 frutos cada, constituindo assim a parcela experimental. $\mathrm{O}$ delineamento experimental utilizado foi o inteiramente casualizado com 22 tratamentos (cultivares) e quatro repetições.

Para as análises, foram retirados os carpelos e as cascas dos frutos, restando assim a amêndoa. Em seguida, foram determinados os teores de umidade e, em amostras secas, os teores de extrato etéreo, proteína, segundo as recomendações do Instituto Adolfo Lutz (BRASIL, 2001), fibra bruta (determinada pelo método de VAN DE KAMER \& VAN GINKEL, 1952) e cinza (segundo AOAC, 2005). O delineamento adotado foi o inteiramente casualizado, com 22 tratamentos (cultivares) e quatro repetições. Os dados quantificados foram submetidos à análise de variância e as médias comparadas pelo teste de Scott-Knott em nível de $5 \%$ de probabilidade.

Posteriormente, foi determinado o perfil de ácidos graxos, sendo trituradas amostras de $100 \mathrm{~g}$ de amêndoas de cada uma das 22 cultivares. As amêndoas trituradas passaram por prensagem hidráulica, em que, por compressão, o óleo em seu estado bruto foi extraído. Em seguida, $5 \mathrm{~mL}$ do óleo obtido em cada repetição das diferentes cultivares, foram esterificados segundo metodologia de HARTMAN \& LAGO (1973). A determinação da composição em ácidos graxos foi realizada por cromatografia de fase gasosa, utilizandose cromatógrafo marca Shimadzu, modelo GC-17A V3, equipado com detector de ionização de chama e coluna capilar de polietilenoglicol DB-Wax (30m de comprimento; $0,25 \mathrm{~mm}$ de diâmetro interno; 0,25 micrometro de espessura), Split na razão de 1:20.

As condições cromatográficas utilizadas foram: temperatura inicial da coluna igual a $60^{\circ} \mathrm{C}$ por um minuto, aumentada a uma taxa de $30^{\circ} \mathrm{C}$ por minuto até a temperatura de $180^{\circ} \mathrm{C}$ por 5 minutos, aquecimento de $3^{\circ} \mathrm{C}$ por minuto até temperatura final da coluna de $230^{\circ} \mathrm{C}$ durante 14 minutos, split na razão de 1:20. O gás de arraste usado foi o nitrogênio, em um fluxo de $2,74 \mathrm{~mL}$ por minuto. A temperatura do injetor foi de $230^{\circ} \mathrm{C}$ e do detector de $250^{\circ} \mathrm{C}$. A identificação dos ácidos graxos foi realizada por comparação entre os tempos de retenção das amostras e dos padrões. A quantificação dos ácidos graxos foi realizada por normalização interna da área do pico, sendo cada pico calculado 
multiplicando-se a sua altura pela largura medida na metade da altura. A composição percentual de ésteres metílicos dos ácidos graxos foi obtida pela razão individual e área total, multiplicando-se por 100, considerando o fator de resposta 1 . Os resultados obtidos foram submetidos à análise de variância, a 5\% de probabilidade pelo teste de Scott-Knott.

\section{RESULTADOS E DISCUSSÃO}

Os resultados obtidos indicam que a maior porcentagem de umidade foi encontrada na cultivar Edson (11,44\%) e as menores em 'HAES 344' $(3,12 \%)$, 'HAES 814' (2,94\%), 'HAES 722' (3,4\%) e 'IAC Campinas-B' (3,19\%) (Tabela 1). Já para o extrato etéreo (teor de lipídeos), os teores significativamente superiores foram encontrados nas cultivares 'Flor Rosa', 'IAC 9-20X', 'HAES 344', 'HAES 849', 'Doroti', '791 Fuji', 'IAC 4-20', 'HAES 722', 'África', 'IAC Campinas-B' e 'HAES 246'.

Para essas cultivares, os valores obtidos para o extrato etéreo estão na faixa citada por
VENKATACHALAM \& SATHE (2006), que relataram o fato de as amêndoas de macadâmia possuírem em torno de $66 \%$ de lipídeos. Algumas cultivares, a exemplo 'Edson', 'HAES 741' e 'HAES 842', apresentaram valores entre $33,13 \%$ a $39,47 \%$, cultivares produtoras de amêndoas menos calóricas (Tabela 1). Segundo SALEEB et al. (1973), a composição em óleo varia entre diferentes espécies e clones de macadâmia.

Para proteína, a maior quantidade foi registrada na cultivar 'IAC 9-20X' (19,24\%) (Tabela 1). Os dados obtidos foram superiores aos relatados por FREITAS \& NAVES (2010), os quais encontraram aproximadamente $8,4 \%$ de proteína nas amostras secas avaliadas. Essa grande variação obtida na composição das amêndoas reforça a importância de avaliar separadamente cada cultivar, visando a obter resultados precisos sobre a espécie em questão. Podese inferir pelos resultados obtidos que as amêndoas apresentam quantidades consideráveis de lipídeos e proteínas e, em decorrência disso, constituem excelentes fontes energéticas.

Tabela 1 - Valores médios da composição química em massa seca (\%) das amostras de amêndoas de 22 cultivares de nogueira-macadâmia. Itapira - SP, 2011.

\begin{tabular}{|c|c|c|c|c|c|}
\hline \multirow{2}{*}{ Cultivares } & \multicolumn{5}{|c|}{ 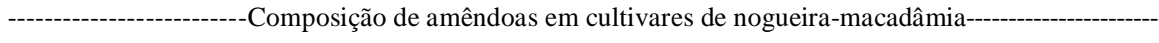 } \\
\hline & Umidade $(\%)$ & Extrato etéreo $(\%)$ & Proteína $(\%)$ & Fibra bruta $(\%)$ & Cinza $(\%)$ \\
\hline 'Edson' & 11,44 a & $33,13 \mathrm{c}$ & $9,29 \mathrm{e}$ & $24,40 \mathrm{~b}$ & $1,40 \mathrm{~b}$ \\
\hline 'HAES 788' & 5,79 e & $47,27 \mathrm{~b}$ & $17,99 \mathrm{~b}$ & $22,95 \mathrm{~b}$ & $1,52 \mathrm{~b}$ \\
\hline 'Beaumont 695' & $10,49 \mathrm{~b}$ & $51,80 \mathrm{~b}$ & $11,20 \mathrm{~d}$ & $9,83 \mathrm{e}$ & $1,39 \mathrm{~b}$ \\
\hline 'Flor Rosa' & $8,08 \mathrm{c}$ & 55,68 a & $13,22 \mathrm{c}$ & $16,56 \mathrm{~d}$ & $0,93 \mathrm{c}$ \\
\hline 'IAC 9-20X' & $5,79 \mathrm{e}$ & 60,26 a & $19,24 \mathrm{a}$ & $6,98 \mathrm{e}$ & $1,00 \mathrm{c}$ \\
\hline 'HAES 344' & $3,12 \mathrm{i}$ & 61,69 a & $13,29 \mathrm{c}$ & $12,14 \mathrm{e}$ & $1,34 \mathrm{~b}$ \\
\hline 'Cannon’ & $4,58 \mathrm{~g}$ & $46,19 \mathrm{~b}$ & $11,83 \mathrm{~d}$ & $19,47 \mathrm{c}$ & $0,97 \mathrm{c}$ \\
\hline 'IAC 9-20' & $3,72 \mathrm{~h}$ & $48,40 \mathrm{~b}$ & $14,53 \mathrm{c}$ & $18,56 \mathrm{c}$ & $1,04 \mathrm{c}$ \\
\hline ‘C160’ & $7,11 \mathrm{~d}$ & $50,64 \mathrm{~b}$ & $11,74 \mathrm{~d}$ & $23,93 \mathrm{~b}$ & $0,45 \mathrm{~d}$ \\
\hline 'HAES 849' & $3,61 \mathrm{~h}$ & 63,22 a & $10,54 \mathrm{~d}$ & 8,55 e & $1,24 \mathrm{~b}$ \\
\hline 'IAC 4-12B' & $8,11 \mathrm{c}$ & $52,05 \mathrm{~b}$ & $11,12 \mathrm{~d}$ & 14,59 e & $1,06 \mathrm{c}$ \\
\hline 'HAES 816' & 6,33 e & $48,89 \mathrm{~b}$ & $13,64 \mathrm{c}$ & $23,10 \mathrm{~b}$ & $1,05 \mathrm{c}$ \\
\hline 'Doroti' & $4,61 \mathrm{~g}$ & $62,80 \mathrm{a}$ & $8,56 \mathrm{e}$ & $8,11 \mathrm{e}$ & $1,14 \mathrm{c}$ \\
\hline '791 Fuji' & $3,51 \mathrm{~h}$ & $64,28 \mathrm{a}$ & $9,81 \mathrm{e}$ & 6,20 e & $1,37 \mathrm{~b}$ \\
\hline 'IAC 4-20' & $3,91 \mathrm{~h}$ & 60,28 a & $11,17 \mathrm{~d}$ & $13,99 \mathrm{e}$ & $1,52 \mathrm{~b}$ \\
\hline 'HAES 814' & $2,94 \mathrm{i}$ & $51,86 \mathrm{~b}$ & $15,47 \mathrm{c}$ & $16,91 \mathrm{~d}$ & $1,31 \mathrm{~b}$ \\
\hline 'HAES 722' & $3,40 \mathrm{i}$ & 56,86 a & $14,21 \mathrm{c}$ & $15,61 \mathrm{~d}$ & $1,82 \mathrm{a}$ \\
\hline ‘África' & $3,94 \mathrm{~h}$ & $62,95 \mathrm{a}$ & $9,92 \mathrm{e}$ & $10,72 \mathrm{f}$ & $1,40 \mathrm{~b}$ \\
\hline 'IAC Campinas-B' & $3,19 \mathrm{i}$ & 60,77 a & $12,14 \mathrm{~d}$ & $9,29 \mathrm{e}$ & $1,35 \mathrm{~b}$ \\
\hline 'HAES 246' & $5,22 \mathrm{f}$ & 59,04 a & $11,89 \mathrm{~d}$ & $12,91 \mathrm{e}$ & $0,93 \mathrm{c}$ \\
\hline 'HAES 741' & $6,80 \mathrm{~d}$ & $39,47 \mathrm{c}$ & $14,19 \mathrm{c}$ & 30,06 a & $1,11 \mathrm{c}$ \\
\hline 'HAES 842' & $4,42 \mathrm{~g}$ & $36,56 \mathrm{c}$ & $14,37 \mathrm{c}$ & 33,32 a & $1,10 \mathrm{c}$ \\
\hline CV $(\%)$ & 5,94 & 9,67 & 7,24 & 11,88 & 13,13 \\
\hline
\end{tabular}

*Médias seguidas pela mesma letra, na mesma coluna, não diferem significativamente entre si, pelo teste Scott-Knott, em nível de 5\% de probabilidade.

Ciência Rural, v.42, n.12, dez, 2012. 
Quanto ao teor de fibra bruta, as cultivares 'HAES 741' e 'HAES 842' (30,06\% e 33,32\%, respectivamente) diferiram significativamente, com valores superiores às demais e, para porcentagem de cinza, a cultivar 'HAES 722' apresentou resultado significativamente superior às demais, com 1,82\% (Tabela 1). Alguns estudos relacionam as fibras com a prevenção de certas enfermidades como câncer de cólon, obesidade, problemas cardiovasculares e diabetes (SALGADO et al., 2008).

Nas análises cromatográficas do óleo extraído, foram encontradas quantidades expressivas dos seguintes ácidos graxos: palmítico, palmitoleico $(\omega-7)$, esteárico, oleico $(\omega-9)$, linoleico $(\omega-6),(\gamma$ linolênico ( $\omega-6)$, linolênico $(\omega-3)$. Os ácidos oleico e palmítico foram detectados em todas as cultivares avaliadas, com predomínio do ácido oleico. Destacaramse significativamente superiores as cultivares HAES 849 e HAES 842, com teores de ácido oleico acima de $80 \%$ (Tabela 2), resultados superiores aos apontados por FREITAS \& NAVES (2010) em amêndoas de nogueira-macadâmia (média de 58,51\%). O ácido oleico é um ácido graxo monoinsaturado que está presente em grande quantidade no azeite de oliva (RIQUE et al., 2002). Ressalta-se que os teores de ácido oleico nessas cultivares estão em níveis superiores aos teores encontrados por OLIVEIRA et al. (2012) em frutos das oliveiras Arbequina (61,30\%) e Grappolo 561 (61,78\%). Por esses resultados, verifica-se a importância de se conhecer o perfil dos ácidos graxos nas diferentes cultivares.

Já para o acido palmítico, os resultados variaram entre 1,37 a $32,3 \%$, em que se destacaram com os maiores valores as cultivares 'Beaumont 695' e 'C160' os menores para 'HAES 849', 'África', 'HAES 842', 'HAES 741' e 'HAES 772'. Quanto ao ácido palmitoleico, este foi detectado em 12 das 22 amostras avaliadas, com destaque para a cultivar 'Edson' (Tabela 2). Quanto ao ácido esteárico, os valores variaram entre 1,25 a $7,13 \%$, destacando-se significativamente superior

Tabela 2 - Porcentagens de ácidos graxos de amêndoas de 22 cultivares de nogueira-macadâmia Itapira - SP, 2011.

\begin{tabular}{|c|c|c|c|c|c|c|c|c|}
\hline Cultivares & $\mathrm{P}$ & PA $(\omega-7)$ & $\mathrm{E}$ & $O(\omega-9)$ & $\mathrm{L}(\omega-6)$ & $\gamma-\mathrm{L}(\omega-6)$ & LI $(\omega-3)$ & $\begin{array}{c}\text { Ácidos } \\
\text { Graxos } \\
\text { NI** }^{* *}\end{array}$ \\
\hline 'Edson’ & $6,96 \mathrm{~d}$ & $29,64 \mathrm{a}$ & - & $50,39 \mathrm{c}$ & - & $6,58 \mathrm{~b}$ & - & $6,43 \mathrm{c}$ \\
\hline 'HAES 788' & $5,15 \mathrm{~d}$ & $21,92 \mathrm{c}$ & - & $48,63 \mathrm{c}$ & $13,10 \mathrm{a}$ & - & $4,56 \mathrm{~b}$ & $6,64 \mathrm{c}$ \\
\hline 'Beaumont 695' & $32,31 \mathrm{a}$ & - & $1,25 \mathrm{~b}$ & $54,72 \mathrm{c}$ & - & $5,89 \mathrm{~b}$ & - & $3,46 \mathrm{~d}$ \\
\hline 'Flor Rosa' & $27,79 \mathrm{~b}$ & - & $2,18 \mathrm{~b}$ & $64,66 \mathrm{~b}$ & - & - & - & $5,37 \mathrm{c}$ \\
\hline 'IAC 9-20X' & $5,22 \mathrm{~d}$ & $19,04 \mathrm{c}$ & - & $45,27 \mathrm{c}$ & - & $11,17 \mathrm{a}$ & $7,06 \mathrm{a}$ & $19,92 \mathrm{a}$ \\
\hline 'HAES 344' & $5,02 \mathrm{~d}$ & $20,75 \mathrm{c}$ & - & $50,05 \mathrm{c}$ & $11,38 \mathrm{a}$ & - & $4,35 \mathrm{~b}$ & $6,16 \mathrm{c}$ \\
\hline 'Cannon' & $4,54 \mathrm{~d}$ & $16,85 \mathrm{~d}$ & - & $47,03 \mathrm{c}$ & $12,07 \mathrm{a}$ & - & $5,25 \mathrm{~b}$ & $14,26 \mathrm{~b}$ \\
\hline 'IAC 9-20' & $17,01 \mathrm{c}$ & $15,13 \mathrm{~d}$ & - & $63,97 \mathrm{~b}$ & $1,03 \mathrm{~b}$ & - & - & $2,86 \mathrm{~d}$ \\
\hline 'C160' & 30,77 a & - & $2,30 \mathrm{~b}$ & $60,61 \mathrm{~b}$ & - & - & - & $6,32 \mathrm{c}$ \\
\hline 'HAES 849' & $1,37 \mathrm{e}$ & $12,28 \mathrm{~d}$ & - & $84,35 \mathrm{a}$ & - & - & - & $0,42 \mathrm{e}$ \\
\hline 'IAC 4-12B' & $6,49 \mathrm{~d}$ & $21,66 \mathrm{c}$ & - & $49,75 \mathrm{c}$ & $9,20 \mathrm{a}$ & - & $3,87 \mathrm{c}$ & $6,39 \mathrm{c}$ \\
\hline 'HAES 816' & $23,34 \mathrm{~b}$ & - & $1,36 \mathrm{~b}$ & $48,76 \mathrm{c}$ & - & 13,18 a & $4,84 \mathrm{~b}$ & $8,52 \mathrm{c}$ \\
\hline 'Doroti' & $18,20 \mathrm{c}$ & - & $1,43 \mathrm{~b}$ & $72,27 \mathrm{~b}$ & - & $1,39 \mathrm{c}$ & - & $3,84 \mathrm{~d}$ \\
\hline '791 Fuji' & $21,12 \mathrm{c}$ & - & $2,84 \mathrm{~b}$ & $69,84 \mathrm{~b}$ & - & $1,28 \mathrm{c}$ & - & $2,20 \mathrm{~d}$ \\
\hline 'IAC 4-20' & $24,28 \mathrm{~b}$ & - & $1,48 \mathrm{~b}$ & $46,64 \mathrm{c}$ & $10,58 \mathrm{a}$ & $2,81 \mathrm{c}$ & - & $14,21 \mathrm{~b}$ \\
\hline 'HAES 814' & $27,01 \mathrm{~b}$ & - & $1,67 \mathrm{~b}$ & $60,19 \mathrm{~b}$ & - & $6,26 \mathrm{~b}$ & - & $4,87 \mathrm{~d}$ \\
\hline 'HAES 722' & $4,82 \mathrm{~d}$ & $24,13 \mathrm{~b}$ & - & $47,25 \mathrm{c}$ & $13,19 \mathrm{a}$ & - & $4,43 \mathrm{~b}$ & $6,18 \mathrm{c}$ \\
\hline 'África' & $1,95 \mathrm{e}$ & $14,83 \mathrm{~d}$ & $7,13 \mathrm{a}$ & $75,31 \mathrm{~b}$ & - & - & - & $0,78 \mathrm{e}$ \\
\hline 'IAC Campinas-B' & $23,74 \mathrm{c}$ & - & $1,55 \mathrm{~b}$ & $55,53 \mathrm{c}$ & $10,49 \mathrm{a}$ & - & - & $8,69 \mathrm{c}$ \\
\hline 'HAES 246' & $24,83 \mathrm{~b}$ & - & $1,53 \mathrm{~b}$ & $47,71 \mathrm{c}$ & $11,88 \mathrm{a}$ & - & $5,69 \mathrm{~b}$ & $8,36 \mathrm{c}$ \\
\hline 'HAES 741' & $4,34 \mathrm{~d}$ & $25,22 \mathrm{~b}$ & - & $45,09 \mathrm{c}$ & - & $11,81 \mathrm{a}$ & $5,10 \mathrm{~b}$ & $8,44 \mathrm{c}$ \\
\hline 'HAES 842' & $2,13 \mathrm{e}$ & $10,82 \mathrm{e}$ & - & $84,05 \mathrm{a}$ & - & - & - & $0,03 \mathrm{e}$ \\
\hline $\mathrm{CV}(\%)$ & 6,87 & 8,25 & 7,75 & 10,15 & 8,20 & 9,96 & 8,21 & 12,13 \\
\hline
\end{tabular}

*Médias seguidas pela mesma letra, na mesma coluna, não diferem significativamente entre si, pelo teste Scott-Knott, em nível de 5\% de probabilidade.

* Palmítico (P), Palmitoleico (PA), Esteárico (E), Oleico (O), Linoleico (L), $\gamma$-Linolênico $(\gamma$-L) e Linolênico (LI).

**Ácidos Graxos Não Identificados (NI). 
a cultivar África (Tabela 2). Os resultados obtidos estão de acordo com FREITAS \& NAVES (2010), os quais verificaram a presença do ácido esteárico no teor de 4,26\% em amêndoas de nogueira-macadâmia.

Com relação ao ácido linoleico, este foi detectado em 9 das 22 cultivares e, com exceção da cultivar 'IAC 9-20', todas as demais mostraram resultados superiores variando entre 9,20 a 13,19\%. O ácido linoleico faz parte da série $\omega-6$ e está presente nas amêndoas de nogueira-macadâmia, óleos de milho, girassol e soja. Os ácidos linolênico ( $\omega$-3) e $\gamma$-linolênico $(\omega-6)$ foram identificados em 15 das 22 cultivares avaliadas, ocorrendo simultaneamente em apenas 3 cultivares ('HAES 741', 'IAC 9-20X' e 'HAES 816') (Tabela 2). $\mathrm{O}$ ácido $\gamma$-linolênico $(\omega-6)$ apresentou grande variação nos valores obtidos de 1,28 a 13,18\% com destaque para 'HAES 816', 'HAES 741' e 'IAC 920X', enquanto, para o linolênico ( $\omega-3)$, os resultados foram mais próximos, na faixa de 3,87 a $7,06 \%$, em que apenas a cultivar 'IAC 9-20X' mostrou-se significativamente superior às demais. $\mathrm{O}$ ácido linolênico da série $\omega-3$ vem sendo alvo de diversos estudos epidemiológicos, pois reduz os triglicerídeos séricos, melhora a função plaquetária e promove ligeira redução na pressão arterial em pacientes hipertensos (RIQUE et al., 2002).

O INSTITUTE OF MEDICINE (2002), por meio das Dietary Reference Intakes (DRIs), recomenda que a ingestão de ácidos graxos essenciais deve ser em torno de $10 \%$ do total de lipídios na dieta, sendo que este valor vai de 5 a $10 \%$ para os ácidos graxos $\omega$ 6 e de 0,6 a 1-2\% para os ácidos graxos $\omega-3$. Estudos realizados por CAMPOS et al. (2004) ressaltam que as dietas ocidentais são deficientes em $\omega-3$. Sendo assim, é importante mencionar que há necessidade do consumo de produtos que contenham valores equilibrados entre os integrantes das séries dos ácidos graxos essenciais.

\section{CONCLUSÃO}

As cultivares 'Flor Rosa', 'IAC 9-20X', 'HAES 344', 'HAES 849', 'Doroti', '791 Fuji', 'IAC 420', 'HAES 722', 'África', 'IAC Campinas-B' e 'HAES 246' apresentaram os maiores teores de extrato etéreo. A maior quantidade de proteína foi registrada na cultivar 'IAC 9-20X'. As maiores porcentagens de fibra bruta foram observadas nas cultivares 'HAES 741' e 'HAES 842 '. As amêndoas de todas as cultivares de nogueiramacadâmia analisadas possuem ácidos palmítico e oleico. Tanto a presença como a quantidade encontrada dos ácidos graxos Linoleico ( $\omega-6)$, linolênico $(\omega-3)$ e $\gamma$-linolênico $(\omega-6)$ apresentaram significativa variação conforme cultivar em questão.

\section{REFERÊNCIAS}

AOAC (Association of Official Analytical Chemists). In: HORWITZ, W. (Ed.). Official methods of analysis of AOAC International. 18.ed. Maryland, USA, 2005. V.2.

BARBOSA, W. et al. Distribuição geográfica e diversidade varietal de frutíferas e nozes de clima temperado no Estado de São Paulo. Revista Brasileira de Fruticultura, v.25, n.2, p.341-344, 2003. Disponível em: <http://www.scielo.br/ scie lo.ph p s s ript = sci_art text \& pid = S $0100-$ $29452003000200042 \& \operatorname{lng}=\mathrm{pt} \& \mathrm{nrm}=\mathrm{iso}>$. Acesso em: 26 set. 2011. doi: dx.doi.org/10.1590/S0100-29452003000200042.

BASTOS, D. C et al. Efeito do ácido indolbutírico na propagação por estacas de dois cultivares de macadâmia (Macadamia integrifolia Maiden \& Betche). Científica Rural, v.11, n.2, p.120-125, 2006.

BRASIL. Agência Nacional de Vigilância Sanitária. ANVISA. Ministério da Saúde. Resolução RDC n.12, de 02 de janeiro de 2001. Dispõe sobre os princípios gerais para o estabelecimento de critérios e padrões microbiológicos para alimentos. Diário Oficial da União. Disponível em: 〈www.anvisa.gov.br>. Acesso em: 08 jan. 2005.

CAMPOS, F.G. et al. Influência da dieta na gênese do câncer colorretal. In: WAITZBERG, D.L. Dieta, nutrição e câncer. São Paulo: Atheneu, 2004. p.47-52.

DALASTRA, I. M. Germinação de sementes de nogueira-macadâmia submetidas à incisão e imersão em ácido giberélico. Ciência e Agrotecnologia, v.34, n.3, p.641-645, 2010. Disponível em: $<$ http://www.scielo.br/scielo.php?script=sci_arttext\&pid=S1413$70542010000300016 \& \operatorname{lng}=$ pt\&nrm=iso $>$. Acesso em: 28 ago. 2012. doi: $10.1590 / \mathrm{S} 1413-70542010000300016$.

FREITAS, J.B.; NAVES, M.M.V. Composição química de nozes e sementes comestíveis e sua relação com a nutrição e saúde. Revista Nutrição, v.23, n.2, p.269-279, 2010. Disponível em: <http://www.scielo.br/scielo.php?script=sci_arttext\&pid=S1415$52732010000200010 \& \operatorname{lng}=p t \& n r m=i s o \& t \operatorname{lng}=p t>$. Acesso em: 26 set. 2011. doi: dx.doi.org/10.1590/S141552732010000200010 .

HARTMAN, L.; LAGO, R.C. Rapad preparation of fatty acid methyl esters from lipids. Laboratory Practice, v.22, n.6, p.475-476, 1973.

INSTITUTO ADOLFO LUTZ. Métodos físico-químicos para análise de alimentos. 4.ed. São Paulo: Instituto Adolfo Lutz, 2005. 1015p.

INSTITUTE OF MEDICINE. Dietary reference intakes (DRI s) for energy, carbohydrate, fiber, fat, fatty acids, choslesterol, protein, and amino acids, Part 1. Washington (DC): National Academy, 2002. 9p.

OLIVEIRA, M.C. et al. Características fenológicas e físicas e perfil de ácidos graxos em oliveiras no sul de Minas Gerais. Pesquisa Agropecuária Brasileira, v.47, n.1, p.30-35, 2012. Disponível em: <http://www.scielo.br/scielo.php?script=sci_arttext\&pid=S0100204X2012000100005\&lng=pt\&nrm=iso\&tlng=pt $>$. Acesso em: 22 fev. 2012. doi: 10.1590/S0100-204X2012000100005. 
PEACE, C.P. et al. Genetic relationships amongst macadamia varieties grown in South Africa as assessed by RAF markers. South African Journal of Plant \& Soil, v.22, n.2, p.71-75, 2005 .

PENONI, E.S. et al. Análise de frutos e nozes de cultivares de nogueira-macadâmia. Ciência Rural, v.41, n.12, p.20802083, 2011. Disponível em: <http://www.scielo.br/ s c i e lo.ph p s cript =s ci_art text \& pid = S 0103 $84782011001200007 \& \operatorname{lng}=p t \& n r m=i s o \& t \operatorname{lng}=p t>$. Acesso em: 22 fev. 2012. doi: 10.1590/S0103-84782011001200007.

RIQUE, A.B.R. et al. Nutrição e exercício na prevenção e controle das doenças cardiovasculares. Revista Brasileira Medicina no Esporte, v.8, n.6, p.244-254, 2002. Disponível em: <http:// www.scielo.br/scielo.php? script $=$ sci_arttext \&pid $=S 1517$ $86922002000600006 \& \operatorname{lng}=\mathrm{pt} \& \mathrm{nrm}=\mathrm{iso} \& \operatorname{lng}=\mathrm{pt}>$. Acesso em: 26 set. 2011. doi: dx.doi.org/10.1590/S1517-86922002000600006.

SALEEB, W.F.C. et al. The oil and protein in nuts Macadamia tetraphylla, L. Johnson, M. integrifolia, Maiden \& Betch, and their F1 hybrids. Journal of American Society for Horticultural Science, v.98, p.453-456, 1973.

SALGADO, J.M. et al. O óleo de abacate (Persea americana Mill) como matéria-prima para a indústria alimentícia. Ciência e Tecnologia de Alimentos, v.28, supl, p.20-26, 2008. Disponível em: <http://www.scielo.br/scielo.php?script=sci_arttext\&pid=S0101$20612008000500004 \& \operatorname{lng}=\mathrm{pt \& nrm}=\mathrm{iso} \& \operatorname{lng}=\mathrm{pt}>$. Acesso em: 27 set. 2011. doi: 10.1590/S0101-20612008000500004.

SOBIERAJSKI, G.R. et al. Noz-macadâmia: produção, mercado e situação no Estado de São Paulo. Informações Econômicas, v.36, n.5, p.25-36, 2006.

VAN DE KAMER, J.H.; VAN GINKEL, L. Rapid determination of crude fiber in cereal. Cereal Chemistry, v.29, n.4, p.239$251,1952$.

VENKATACHALAM, M.; SATHE, S.K. Chemical composition of selected edible nut seeds. Journal of Agricultural and Food Chemistry, v.54, n.13, p.4705-4714, 2006. 